\title{
Influences of Network Video on Pay TV--An Analysis Based on Guangzhou
}

\author{
Fanbin Zeng $^{1} \&$ Fangzhou Cheng ${ }^{1}$ \\ ${ }^{1}$ College of Journalism, Jinan University, Guangzhou, China \\ Correspondence: Fanbin Zeng, College of Journalism, Jinan University, Guangzhou 510632, China. E-mail: \\ zengfanbin@vip.sina.com
}

Received: July 11, 2012 Accepted: July 19, 2012 Online Published: August 17, 2012

doi:10.5539/ass.v8n11p13

URL: http://dx.doi.org/10.5539/ass.v8n11p13

This Project was financed by 2012 Humanities and Social Science Youth Foundation of the Ministry of Education of China (Grant Number: 12YJC860052; Grant Title: Effect of Time Spent Online and Patterns of internet use on Real-life Political Participation: Based on Empirical Study on Internet Users in Guangzhou)

\begin{abstract}
This article is going to discuss on how the audience know and evaluate network video and pay TV and whether the popularity of network video will bring about influences to pay TV. This research is based on a survey conducted in November 2011 of which the respondents were residents living in Guangzhou at the age of 16 and above who had applied internet in the past half year. A comparable analysis of the findings in this survey and the national statistics reveals some common characteristics among the audience using the network video: 1) The audience who use the network video are mainly young people at an age of 10 to 39. 2) Appearance of network video (IPTV) does have influences on the frequency and perception of watching the traditional TV by the audience. 3) It is true that more and more audience come into contact with the network video, but the intention of the audience to purchase network video is not strong. Through the survey and analysis, it is found that influences of network video on the traditional TV (including digital pay TV) are that it has appealed young audience to watch, but the network video can only attract the audience to watch, and may not attract them to pay to watch. Therefore, the direct influence of network video on pay TV is limited.
\end{abstract}

Keywords: network video, pay TV, traditional TV

\section{Introduction}

Network video is a kind of internet application of watching video programs on the internet by way of the instruments of browser and play software of client-end. China Internet Network Information Center (CNNIC) promulgated "29th China Internet Development Statistical Report" (hereinafter abbreviated as "Report") in Beijing in January 2012. The "Report" indicates, the number of Chinese netizens by the end of December 2011 has surpassed 0.5 billion. The popularity rate of internet use increased by 4 percentage points compared with that in 2010. In 2011, at the time when the usage rate of a large part of internet entertainment application continued to go down, the usage rate of network video presented a tendency of counter increase and the development situation of network video industry is relatively promising. Furthermore, according to "Study Report on Application of Network Video by Chinese Netizens in 2011" released by CNNIC, the scale of network video users in China kept a tendency of stable increase and increased gradually from 161 million at the end of 2007 to 325 million at the end of 2011 and the proportion of video users to all the netizens increased from $62.1 \%$ at the end of 2012 to $63.4 \%$ at the end of 2011. Network video has become an important channel for people to acquire such digital content of film, TV play and video. The value of media is rapidly growing and its position in the internet industry continues to rise.

In order to acquire more content options, quite a lot of people choose to watch a video on the internet that is relatively not strictly regulated by the government. Although video content on the internet has the issue of legality and the low resolution of video makes it difficult to endure, it has to be acknowledged the network video has really attracted a large number of people, especially the young generation owing to its abundant and rich 
content and its function of broadcasting real-time programs, as well as especially its characteristics of free charge. This, to a certain extent, disperses the current TV audience. Ever since 2011, the network video industry in China has maintained a momentum of highly rapid growth and the developmental prospect of network video industry is widely favored. Thus, enterprises speed up to expand their pace. Meanwhile, the traditional web portals also march towards this field one after another through different approaches. As a result, competition within the industry becomes increasingly fierce.

At present, the network video in China contains content of two categories of subject supply. One category is network video provided by non-traditional media and the other is network video provided by traditional media. First of all, network video provided by non-traditional media is introduced here. Development of internet users has greatly promoted development of network audio and video business. For the time being, network video provided by domestic non-traditional media mainly contains the two major categories of vertical video website and portal video. Vertical network video is mainly represented by Youku, Tudou, PPLive, PPS, and JoyVideo, etc., whereas portal video is mainly represented by Sohu. Among vertical network videos, Youku, Tudou and Ku6 are greatly criticized for copyright infringement as the net friends upload shared models; JouVideo and LeTV as well as Sohu mainly play genuine video; PPLive and PPS mainly depend on client-end software to broadcast serialized TV plays. On the other hand, from the perspective of the business provided by audio and video websites, these websites can be classified into audio and video sharing, on-line video selection, audio and video search and streaming media. Audio and video sharing mainly contains such professional audio and video sharing websites as Tudou and Youku, etc., and such portal audio and video channels as Sina. On-line video selection refers to websites that provide selection or broadcast of audio and video, such as, WAP, TV and 116.com, etc. Audio and video search contains websites that provide audio and video search service, including Baidu video search. Streaming media refers to websites that offer audio and video download service and browsing service represented by Thunder that employs streaming media technique.

The other kind is network video provided by the traditional media. In order to respond to challenges of the new media, a multitude of domestic radio and broadcasting media, including CCTV and Shanghai Media Group, have begun to enter the network video field. On January 1, 1999 when CCTV officially opened its internet website, "CCTV News" was online that evening and becomes the earliest domestic TV program that is broadcast on the internet. On June 1 that same year, Hongqiao net opened its IPTV service and broadcast three live broadcasting youngster programs in an interactive way. The most obvious feature of this program is its interaction, real time and multi-media communication. At the end of 2001, the Xinhua News Agency cooperated with China Telecom to launch IPTV platform; in 2004, Beijing TV launched its IPTV station "ZGBJTV"; on May 31, 2004, CNTV, one of the biggest network video operators in China, opened IPTV service of CCTV. With program resources of CCTV, CNTV offered video-on-demand service for its users through broadband internet. CNTV collected the historical data of hundreds of thousands of hours ever since establishment of CCTV and, meanwhile, newly added several decades of hours of real time TV programs each day, which was a milestone of IPTV in breakthrough of content. As for users, they could request for broadcasting of their favorite programs of all columns of CCTV at any time and they could also watch high quality TV plays online.

After the Spring Festival in 2005, China National Radio set up CNTV. In May 2005, Shanghai TV subordinate to Shanghai Media Group was awarded with the first IPTV and mobile TV whole business license issued by The State Administration of Radio Film and Television (SARFT). Afterwards, Shanghai Media Group invested to set upBesTV and SMGBB, etc., and developed the new media business represented by network video. SMGBB officially launched "BBTV.cn" in 2009; on January 2008, the new media platform of Hunan TV "humantv.com" got online and set up its market status of "video portal". In 2009, imgo.tv subordinate to hunantv.com was separated and was operated as an independent brand in the market. In the same year, the Xinhua News Agency officially broadcast special line of network video, including a variety of program forms, such as, direct live broadcast, multi-point TV line connection, and studio interview, etc., which had the style of "modern, fashion and vitality". This was a video news broadcasting line that was paralleled with the word news line and picture news line of the Xinhua News Agency. It was broadcast in succession for 24 hours one day and opened its Chinese TV news service on kaixin001.com which was extremely popular at that time. The English TV news line of the Xinhua News Agency began its first broadcasting each day for 90 minutes and was conveyed to Chinese users through the satellite link, whereas users in other countries and regions mainly received it on the internet. Based on abundant news information resources and audio program resources, "Chinese Radio Network" subordinate to China National Radio set up a "Chinese broadcast network" that was centered with CCTV, depended on all local TVs across the country and was faced to the whole country and the whole world. Altogether, 64 professional channels were set up, including news, finance, sports, music, book, automobile, 
tourism, military, nationality and issues in Taiwan and there were more than 400 columns. The total amount of audio data was 2TB. The website offered internet direct broadcasting of the 9 channels of China National Radio and on-line selection service of more than 270 key columns with the first class streaming media audio broadcasting technique in the country that took the lead in the international world. On December 28, 2009, "cntv.cn" was officially broadcast. Broadcast of cntv.cn was an important milestone in development of the newly emerging media. With official broadcasting online of CNTV, the several radio and TV army groups of CCTV, Shanghai Media Group, PhoenixTV, Hunan Radio and TV and Zhejiang Radio and TV with official background had seen their initial scale in the market domain of the network video.

Whether in the case of network video provided by non-traditional media or in the case of network video provided by traditional media, most of them are free TV, while pay TV in China is mainly broadcast in pay channels of digital televisions. These two are entire different both in terms of channel and in terms of content. Since network video resorts to the internet platform and can be retrieved, with great capacity, watch at any time has become its primary superiority to pay TV at present. In addition, major video websites in China paid much attention to offering high quality film and TV content with copyright in 2011. With constant enrichment of content resources, netizens got accustomed to surf on the internet to watch a film and drama series of hot broadcast TV play and utilization ratio of Chinese network video gradually recovered to steadiness. In 2011, war of copyright among video websites became fiercer and all the websites expensed a great deal of resources and energy to purchase the copyright of hot broadcast films and teleplays. At the time when these websites enriched the reserve of video content, a lot of them put forward the strategy of self manufactured content and improved the variety and subject of video content. In order to realize differentiation competition, video websites extended their business in news content, cartoon, entertainment and documentary, etc., and even began to invite professional TV producers to take charge of video business, which appealed to different groups of people with different interests and demands.

Then, what kind of differences there are on earth between network video and pay TV contacted by the audience and how they know and evaluate network video and pay TV? Whether will popularity of network video bring about influences to pay TV? This article is going to make a discussion.

\section{Related Issues in Literature Review}

The above analysis has concerned with literature about pay TV. In the following, the authors mainly analyze relevant studies about network video (or IPTV).

In terms of books, Zhang Haichao gave an introduction to relevant situation of IPTV in the book "Eyeball Economy --- Survival of Digitalization and Industrialization of Chinese TV", mainly including management policy of IPTV, status quo, technical condition and users of IPTV and charge situation of ITPV, and also pointed out several major aspects in which IPTV was distinguished from other TV communication patterns. Furthermore, Huang Shengmin et al. made a preliminary summary of the developmental background of ITPV and problems which might be encountered at the initial stage of ITPV in the book "New Theory of Operation of Radio and TV Media Industry", such as, "operation mode problem, industrial policy problem, hardware facility problem, standard problem and content problem". (Huang Shengmin \& Zhou Yan, et al., 2005) Huang Chuxin (2008) made a general explanation to development of Chinese IPTV in "Change and Reconstruction --- Development Condition and Direction of Chinese IPTV". He began with its definition, including technique of IPTV, media ecological landscape, meaning of communication, development mode of IPTV and problems encountered, and predicted developmental tendency of IPTV in the future. The whole book is a comprehensive description of IPTV and is representative. Wang Mingxuan (2009), in "TV to Die out --- Approaching of Networking and Interactive Video Era", made a comparison between differences of development of Sino-American network video from a novel perspective and in humorous language and analyzed the huge impact of IPTV on the traditional TV. All the above books concentrated on macro and descriptive analysis in their study on network video, but were lacking in micro and demonstrative analysis.

In terms of thesis, Shi Changshun from Huazhong University of Science and Technology published "IPTV and Its Broadcasting Characteristics" in "Modern Communication". The author enumerated basic characteristics of IPTV, such as, "super-spatial information selection", "individualized information service", "interactive information communication (Wang Mingxuan, 2009)". In "Thought on Development of IPTV", Lv Liang'an from Sichuan University began with development condition of IPTV, analyzed the bottleneck of IPTV with case study as the basis, and proposed suggestions in terms of supervision system, license issuance, integration of upstream and downstream of the industrial chain and cultivation of consumption habits of users. Shi Xiaofeng (2009) from Graduate School of Sichuan Academy of Social Sciences, made an analysis of the motive power and 
advantages of IPTV in "Study on Development Condition of Chinese IPTV", and put forward the critical feature of innovative profit mode in an effort to resolve developmental issues of IPTV. Furthermore, he expounded the developmental tendency of IPTV in the future, mentioned that it was necessary to reshuffle the entire market of IPTV in order for the IPTV to develop and also discovered live broadcast of the roll booster of IPTV --competitive sports events.

In terms of empirical research, Zhang Li (2010) selected the university students as the respondents and made a rational evaluation on the communication effects of network video advertisements through a survey to understand the behavior of university students to use network video and the attitudes of university students towards network video advertisements. Furthermore, she also put forward suggestions to improve and enhance the communication effects of network video advertisements. Deng Xiaoxuan (2010) took university students in $\mathrm{Xi}$ 'an as an example and made a relevant survey and analysis of key influencing factors and basic information in university students' usage of IPTV. With the two theoretical frameworks of Diffusion of Innovation Theory and Uses and Gratifications Theory, the author analyzed key factors affecting university students' usage of IPTV from the three aspects of perception characteristics, perception prevalence and perception demand. The survey showed that, perception of relative superiority and usability of IPTV affected university students' usage of IPTV and perception prevalence and perception of demand on consumption of time, demand on acquisition of information, demand on emotional exchange and demand on relaxing feelings all exerted influences on university students' usage of IPTV. All the above studies regarded university students as the object and were difficult to extend to ordinary audience. Study report on application of network video by Chinese netizens worked out by CNNIC from 2009 to 2011 had more descriptive statistics. Although these studies are worthy of our reference, they are lacking in delicate survey and analysis of a specific city, especially relevant variables of multiple regression analysis.

Jonathan Taplin, professor in Annenberg School for Communication of University of Southern California, analyzed "TV media will trigger a worm-eaten transformation or revolution from scarcity of channels at a simulation era to abundance of channels at a digital era." (Jonathan Taplin, 2005). In his article, the author put forward the five elements to be changed, including content manufacturer, content developer, telecom provider and advertiser, etc. As for how users used IPTV, some researchers (Note 1) proposed an IPTV usage model with the ultimate variables of perceived usefulness, perceived ease-of-use, perceived happiness and perceived price on the basis of individual innovation and computer competence. Although these foreign studies have provided enlightenment, they are not likely to be applied directly into reality in China.

\section{Research Methodology}

\subsection{Background of Sample Data}

The data of this statistical survey was collected in November 2011 and the survey respondents were generally residents at the age of 16 and above currently living in Guangzhou who had applied internet in the past half year. This survey was an internet one and was also a quota survey conducted with the instrument of QQ, a commonly used internet communication instrument by Chinese netizens currently. Although quota survey was different from the traditional proportionate stratified sampling, it could generate data that were comparable with the general characteristics (Putnam, 2000; Putnam \& Yonish, 1999). The specific quota process was as follows. Step one: to $\log$ in with a QQ number and register one if there was no QQ number; Step two: to click on the bottom right corner button "Search"; Step three: to select "Query by Criteria" in the Pop-up Window "Search Mode", select "China" in the option of "Country", and select "Guangzhou" in the option of area. Other settings were quotas according to the data about gender and age in the statistical data about netizens in the past few years. Each student need complete nine effective questionnaires: 2 persons at the age from 16 to 22,3 persons at the age from 23 to 30,2 persons at the age from 31 to 40 and 2 persons at the age above 40 . Besides, the proportion of male to male among these nine persons was 5:4, namely, 5 males and 4 females. And the specific procedure to search for the respondents was as follows:

A: First of all, search respondents at the age from 16 to 22 whose QQ was on-line and interview them in their on-line sequence. It was OK to successfully interview him (her) whether he (she) was male or female. Yet, the gender of the respondent had to be recorded according to the questionnaire after a successful interview. The interview should come to an end when the number of male respondents reached 5 and the number of female respondents reached 4. (Special note for the interview: one QQ number could only be interviewed once and if any QQ that had been interviewed, the interview would change to another QQ number).

B: Then, search respondents at the age from 23 to 30 whose QQ was on-line and interview them in their on-line sequence. It was OK to successfully interview him (her) whether he (she) was male or female. Yet, the gender of 
the respondent had to be recorded according to the questionnaire after a successful interview. The interview should come to an end when the number of male respondents reached 5 and the number of female respondents reached 4 .

C: Then, search respondents at the age from 31 to 40 whose QQ was on-line and work out the number of males and females that were interviewed in the last two interviews. Gender of the remaining interview respondents should be confined when the number of male respondents reached 5 and merely female respondents could be interviewed. Similarly, Gender of the remaining interview respondents should be confined when the number of female respondents reached 4 and merely male respondents could be interviewed.

D: Finally, search respondents at the age above 40 whose QQ was on-line and work out the number of males and females that were interviewed in the last three interviews. Gender of the remaining interview respondents should be confined when the number of male respondents reached 5 and merely female respondents could be interviewed. Similarly, Gender of the remaining interview respondents should be confined when the number of female respondents reached 4 and merely male respondents could be interviewed.

In addition, if the "the fourth subject: Which district of Guangzhou do you live in?" in the basic personal information of the Fifth Section was finished, this questionnaire was an effective one, but this did not mean end of the survey and it had to go on. Investigators who took part in the interview were students who took as an elective course "Operation and Management of Internet" and "Introduction to Internet Communication" of the author. In order to ensure the reliability of the interview, the investigators had to fill in the number of QQ in this successful interview and signed their own names. Ultimately, altogether 1317 interviewees were successfully interviewed. After the survey was finished, the data were pre-processed, value of variables and the logic relationship between variables were checked. After all unqualified samples and data having a missing value were entirely deleted and processed, altogether 1162 data were obtained. The passing rate of the questionnaire was $88.2 \%$. The following data were to be analyzed with these 1162 data.

Since there was no way to find out the entire survey data about netizens living in Guangzhou, we could only make a comparison between the sample data and data about all Chinese netizens and data about distribution of netizens living in Guangzhou.

3.2 Comparison between the Sample Data with Structure of Netizens in the China Internet Development Statistical Report (July, 2011)

Table 1. Comparison of sample data and china internet development statistical report in July, 2011

\begin{tabular}{lll}
\hline Variable & Sample data (\%) & Statistical data (\%) \\
\hline Gender & 55.2 & 55.1 \\
Male & 44.8 & 44.9 \\
Female & & \\
Age (Note 1) & 9.0 & 10.7 \\
$16-19$ & 49.9 & 37.8 \\
$20-29$ & 21.7 & 28.5 \\
$30-39$ & 15.6 & 14.2 \\
$40-49$ & 3.5 & 5.9 \\
$50-59$ & 0.3 & 2.9 \\
$60+$ & & \\
Educational background & 1.2 & 8.7 \\
Primary school and below & 8.4 & 35.1 \\
Junior middle school & & 33.9 \\
Senior middle school or technical & 25.1 & 10.5 \\
secondary school & 22.4 & 11.7 \\
Junior college & 42.9 & \\
Undergraduate &
\end{tabular}




\section{Distribution of occupation}

Student

Self-employed entrepreneurs/Free agent

Unemployed and laid-off

Professional technician

Manufacturing/producing employees

Commercial/service employees

Common staff in enterprise/corporate

Mid-level managerial personnel in enterprise/corporate

Top managerial personnel in enterprise/corporate

Common staff in Party and government offices and public institution

Leaders in Party and government offices and public institution

$\begin{array}{llc}\text { Farmer } & 0.1 & 5.3 \\ \text { Retired } & 0.5 & 2.7 \\ \text { Others } & 5.7 & 1\end{array}$

Note 1: Considering the actual need, this survey did not investigate respondents below the age of 16, so the statistical data also did not include the proportion of these respondents and the proportion of the respondent above the age of 16 was re-calculated.

3.3 Comparison between the Sample Data and the Data about the Sixth Nationwide Population Census (Guangzhou, 2010)

Table 2. Comparison between the sample data and the data about the sixth nationwide population census in Guangzhou in 2010

\begin{tabular}{lll}
\hline Regional distribution of households & Sample data (\%) & Statistical data (\%) \\
\hline Liwan District & 8.6 & 7.1 \\
Yuexiu District & 13.5 & 9.1 \\
Haizhu District & 13.2 & 12.3 \\
Tianhe District & 26.5 & 11.3 \\
Baiyun District & 10.9 & 17.5 \\
Huangpu District & 3.8 & 3.6 \\
Panyu District & 11.4 & 13.9 \\
Huadu District & 5.2 & 7.4 \\
Nansha District & 2.5 & 2.1 \\
Luogang District & 0.6 & 2.9 \\
Zengcheng District & 2.4 & 8.6 \\
Conghua District & 1.4 & 4.7
\end{tabular}

It could be seen through the comparison between the sample data and the structure of netizens in the China Internet Development Statistical Report (July, 2011), the sample data and the statistical data were almost identical in terms of gender, with an error less than $1 \%$. In terms of age, the sample data at the age from 20 to 29 
were more than $10 \%$ or so than the statistical data, as QQ was a favorite of the young people. In terms of educational background, the sample data about those (who used QQ) were higher than the statistical data about (ordinary netizens) and options of occupational distribution were not greatly distinguished. In the comparison between the sample data and the data about the sixth nationwide population census in Guangzhou in 2010, the sample data were almost identical with the statistical data, except that distribution in some areas was imbalance. For example, the sample data were larger in Tianhe District which was because Tianhe District was an area where information technology companies and office buildings were centralized. Nevertheless, generally speaking, the sample data was adequately representative as for all netizens living in Guangzhou in terms of gender distribution, age distribution and regional distribution.

\section{Research Findings}

\subsection{Comparison of Frequency of Watching the Traditional TV and Network Video (IPTV)}

Among the 1162 respondents, to the question of frequency of watching the traditional TV, there were $2.2 \%$ who answer "never watch", $17 \%$ who answered "hardly watch", 44.7\% who answered "sometimes watch", 25.8\% who answered "relatively often watch", $6 \%$ who answered "often watch" and " $1.3 \%$ who answered "have no idea/unwilling to answer".

Among the 1162 respondents, to the question of frequency of watching network video (IPTV), there were $4.4 \%$ who answered "never watch", $18.2 \%$ who answered "hardly watch", $32.6 \%$ who answered "sometimes watch", $26 \%$ who answered "relatively often watch", $16.4 \%$ who answered "often watch" and $1.5 \%$ who answered "have no idea/unwilling to answer".

Through a comparison between the frequency of watching the traditional TV and network video (IPTV) among these 1162 Guangzhou netizens, we get the following Table 4:

Table 3. Comparison between the frequency of watching the traditional TV and network video (IPTV) among the 1162 Guangzhou netizens

\begin{tabular}{lcc}
\hline & $\begin{array}{c}\text { Frequency of watching the } \\
\text { traditional TV }\end{array}$ & $\begin{array}{c}\text { Frequency of watching network video } \\
\text { (IPTV) }\end{array}$ \\
\hline never watch & $2.2 \%$ & $4.40 \%$ \\
hardly watch & $17.0 \%$ & $18.20 \%$ \\
sometimes watch & $44.70 \%$ & $32.60 \%$ \\
relatively often watch & $25.80 \%$ & $26 \%$ \\
often watch & $6 \%$ & $16.40 \%$ \\
have no idea/unwilling & $1.30 \%$ & $1.50 \%$ \\
to answer & & \\
\hline
\end{tabular}

From the above figures, as for netizens who now live in Guangzhou, the frequency of often watching the traditional TV is merely $6 \%$, while the frequency of often watching the IPTV is $16.4 \%$, and the frequency of sometimes watching the traditional TV is $44.7 \%$, which is higher than the frequency of $32.6 \%$ in sometimes watching IPTV.

Furthermore, we took the frequency of watching the traditional TV as the dependent variable and gender, age, educational background and average monthly income as the independent variables to make a regression analysis. It was discovered that, age had a significantly positive influence on the frequency of watching the traditional TV $(B=0.150, p<0.001)$. That is, the larger the age, the higher the frequency of watching the traditional TV. By contrast, educational background had a significantly negative influence on the frequency of watching the traditional TV $(\mathrm{B}=-0.76, \mathrm{p}<0.05)$. That is, the higher the educational background, the lower the frequency of watching the traditional TV. By summarizing these two variables, it could be discovered that, now the group of audience who watch the traditional TV have a large age and low educational background. 
Table 4. Regression analysis of the frequency of watching the traditional $\mathrm{TV}^{\mathrm{a}}$

\begin{tabular}{|c|c|c|c|c|c|c|}
\hline \multirow[b]{2}{*}{ Model } & & \multicolumn{2}{|c|}{ Unstandardized Coefficients } & \multirow{2}{*}{$\begin{array}{c}\begin{array}{c}\text { Standardized } \\
\text { Coefficients }\end{array} \\
\text { Beta }\end{array}$} & \multirow[b]{2}{*}{$\mathrm{t}$} & \multirow[b]{2}{*}{ Sig. } \\
\hline & & B & Std. Error & & & \\
\hline \multirow[t]{5}{*}{1} & (Constant) & 3.162 & .151 & & 20.923 & .000 \\
\hline & Gender & -.104 & .057 & -.054 & -1.848 & .065 \\
\hline & Age & .015 & .003 & .150 & 4.692 & .000 \\
\hline & $\begin{array}{l}\text { Educational } \\
\text { background }\end{array}$ & -.066 & .026 & -.076 & -2.559 & .011 \\
\hline & $\begin{array}{l}\text { Average } \\
\text { monthly } \\
\text { income }\end{array}$ & -.004 & .010 & -.013 & -.406 & .685 \\
\hline
\end{tabular}

a. Independent variable: the frequency of watching the traditional TV

Furthermore, we took the frequency of watching IPTV as the dependent variable and gender, age, educational background and average monthly income as the independent variables to make a regression analysis. It was discovered that, age had a significantly negative influence on the frequency of watching the traditional TV $(\mathrm{B}=-0.238, \mathrm{p}<0.001)$. That is, the larger the age, the lower the frequency of watching IPTV. By contrast, educational background had a significantly positive influence on the frequency of watching IPTV $(B=0.082$, $\mathrm{p}<0.05$ ). That is, the higher the educational background, the higher the frequency of watching the traditional TV. By summarizing these two variables, it could be discovered that, now the group of audience who watch IPTV have a small age and high educational background. This analysis result was exactly contrary to the result of watching the traditional TV. It also indicated that, development of IPTV attracted the young audience with a high educational background, which also caused attack to the traditional TV.

Table 5. Regression analysis of the frequency of watching IPTV ${ }^{\mathrm{a}}$

\begin{tabular}{|c|c|c|c|c|c|c|}
\hline \multirow[b]{2}{*}{ Model } & & \multicolumn{2}{|c|}{ Unstandardized Coefficients } & \multirow{2}{*}{$\begin{array}{c}\begin{array}{c}\text { Standardized } \\
\text { Coefficients }\end{array} \\
\text { Beta }\end{array}$} & \multirow[b]{2}{*}{$\mathrm{t}$} & \multirow[b]{2}{*}{ Sig. } \\
\hline & & B & Std. Error & & & \\
\hline \multirow[t]{6}{*}{1} & (Constant) & 3.997 & .173 & & 23.057 & .000 \\
\hline & Gender & -.087 & .065 & -.038 & -1.342 & .180 \\
\hline & Age & -.028 & .004 & -.238 & -7.618 & .000 \\
\hline & $\begin{array}{l}\text { Educational } \\
\text { background }\end{array}$ & .083 & .029 & .082 & 2.824 & .005 \\
\hline & $\begin{array}{l}\text { Average } \\
\text { monthly }\end{array}$ & -.015 & .011 & -.040 & -1.312 & .190 \\
\hline & income & & & & & \\
\hline
\end{tabular}

a. Independent variable: the frequency of watching IPTV

We further analyzed whether network video (IPTV) had impacts on watching the traditional TV and we got the following Table 6 . 
Table 6. Whether network video (IPTV) has influence upon watching the traditional TV

\begin{tabular}{llrrrr}
\hline & Frequency & Percent & Valid Percent & Cumulative Percent \\
\hline Valid & Great impact & 225 & 19.4 & 19.4 & 19.4 \\
& Somewhat impact & 400 & 34.4 & 34.5 & 53.9 \\
& No great impact & 315 & 27.1 & 27.2 & 81.0 \\
& Hardly any impact & 111 & 9.6 & 9.6 & 90.6 \\
& No impact & 66 & 5.7 & 5.7 & 96.3 \\
& have no & & & & \\
& idea/unwilling to & 43 & 3.7 & 3.7 & \\
& answer & & & & \\
& Total & 1160 & 99.8 & 100.0 & \\
Missing & System & 2 & .2 & & \\
Total & & 1162 & 100.0 & &
\end{tabular}

Among the 1162 respondents, except for two respondents with a missing value, to the question "Whether emergence of network video (IPTV) has any impact on the frequency of watching the traditional TV", there were $19.4 \%$ who answered "There are great impacts", $34.5 \%$ who answered "There are somewhat impacts", $27.1 \%$ who answered "No great impact", 9.6\% who answered "Hardly any impact", 5.7\% who answered "No impact" and 3.7\% who answered "Have no idea/unwilling to answer". There were 53.9\% $(19.4 \%+34.5 \%)$ who answered there were impacts, which was higher than the proportion of $15.3 \%(9.6 \%+5.7 \%)$ who answered there was no impact. Thus, generally speaking, the audience believed that emergence of network video (IPTV) had impact on the frequency of watching the traditional TV by the audience. A general view on the transition from the actual behavior of the watching frequency to the cognition in impacts of network video (IPTV) on the traditional TV, network video (IPTV) is currently a competitive competitor of the traditional TV which also contains digital pay TV.

\subsection{Cognition of Characteristics of Network Video (IPTV)}

In comparison between network video (IPTV) with the traditional TV, the following table contains the proportion of answers by the respondents.

Table 7.

\begin{tabular}{lccccc}
\hline & $\begin{array}{l}\text { Strongly } \\
\text { disagree }\end{array}$ & Disagree & Neutral & Agree & $\begin{array}{l}\text { Strongly } \\
\text { disagree }\end{array}$ \\
\hline $\begin{array}{l}\text { (1) Network video (IPTV) is more abundant and } \\
\text { diversified video resource than the traditional TV }\end{array}$ & 1.4 & 5.3 & 29.9 & 44.8 & 18.4 \\
$\begin{array}{l}\text { (2) Network video (IPTV) is more fast updated } \\
\text { and allows users to automatically search their } \\
\text { favorite program and watch at any time }\end{array}$ & 0.7 & 4.5 & 21.9 & 47.1 & 25.6 \\
$\begin{array}{l}\text { (3) In watching the network video (IPTV), the } \\
\text { audience may realize bilateral interaction through } \\
\text { on-line comments and anonymous online } \\
\text { comments, etc. }\end{array}$ & 0.9 & 5.5 & 39.6 & 38.8 & 15.1 \\
$\begin{array}{l}\text { (4) There are more popup advertisement windows } \\
\text { in watching the network video (IPTV) }\end{array}$ & 3.0 & 3.6 & 25.1 & 36.9 & 31.2 \\
$\begin{array}{l}\text { (5) The picture quality, feeling and comfortability } \\
\text { of watching the traditional TV is better than } \\
\text { watching the network video (IPTV) }\end{array}$ & 1.9 & 12.8 & 36.1 & 34.7 & 14.5 \\
$\begin{array}{l}\text { (6) Vulgarness, violence and pornography of } \\
\text { watching the network video (IPTV) has not yet } \\
\text { been completely purified. }\end{array}$ & 4.3 & 8.6 & 39.2 & 34.6 & 13.3 \\
\hline
\end{tabular}


From the above figures, it can be found, the respondents who chose "Agree" and "Strongly agree" in answering all the above judgments are more than those who chose "Strongly disagree" and "Disagree". That is to say, a large majority of netizens approved the above judgments. Superiority of network video (IPTV) to the traditional TV is as follows: more abundant and diversified video resource, fast update, automatically searching for the favorite program and watch at any time; realization of bilateral interaction through on-line comments and anonymous online comments, etc. However, the inferiority of the network video (IPTV) to the traditional TV is as follows: more popup advertisement windows, and picture quality, feeling and comfortability of the traditional TV are better than the network video (IPTV); vulgarness, violence and pornography of watching the network video (IPTV) has not yet been completely purified.

\subsection{Comparison of the Intention of Watch Network Video (IPTV) and Pay Channel of Digital TV}

Among the 1162 respondents, as to the question "Whether you are willing to pay to watch the network video (IPTV)?", there were 3.0\% who answered "Totally willing", 7.6\% who answered "Almost willing", $25.6 \%$ who answered "Half willing and half unwilling", 28.3\% who answered "Almost unwilling", 29.2\% who answered "Totally unwilling" and $6.4 \%$ who answered "Have no idea/unwilling to answer". Generally speaking, the netizens still do not approve of paying to watch the network video (IPTV).

Yet, Among the 1162 respondents, as to the question "Whether you are willing to watch the pay channels of digital TV?", there were 6.3\% who answered "Totally willing", 13.3\% who answered "Almost willing", 28.5\% who answered "Half willing and half unwilling", 22\% who answered "Almost unwilling", 21.9\% who answered "Totally unwilling" and 7.9\% who answered "Have no idea/unwilling to answer".

Table 8. Cognitive comparison between the intention to pay to watch the traditional TV and network video (IPTV)

\begin{tabular}{lrr}
\hline & $\begin{array}{c}\text { Willing to pay to watch the } \\
\text { network video (IPTV) }\end{array}$ & $\begin{array}{c}\text { Willing to pay to watch the pay } \\
\text { channels of digital TV }\end{array}$ \\
\hline Totally willing & $3.0 \%$ & $6.3 \%$ \\
Almost willing & $7.6 \%$ & $13.3 \%$ \\
Half willing and half & $25.6 \%$ & $28.5 \%$ \\
unwilling & $28.3 \%$ & $22.0 \%$ \\
Almost unwilling & $29.2 \%$ & $21.9 \%$ \\
Totally unwilling & $6.4 \%$ & $7.9 \%$ \\
Have no idea/unwilling & & \\
to answer & &
\end{tabular}

From the above two groups of figures, it can be found that, although network video (IPTV) has had influences upon TV (including pay TV), the proportion of $19.6 \%(6.3 \%+13.3 \%)$ of the intention to watch pay channels of digital TV is still higher than the proportion of $10.6 \%(3.0 \%+13.3 \%)$ of the intention to watch the network video (IPTV). This conclusion of the study is similar to the conclusion of "Study Report on Application of Network Video by Chinese Netizens in 2011". It was indicated in "Study Report on Application of Network Video by Chinese Netizens in 2011" that, "1). The proportion of video users at present who pay to watch the network video ess extremely low. If those users who paid once or twice now and then or once for several months were excluded from the premium users, the proportion of users was merely $1.5 \%$ who had relatively a stable pay habit among the video users. The primary motive to pay by users was to watch more and better resources or that they might not find any free resources they wanted to watch. 2). Among the users who did not pay to watch the video, there were approximately three quarters of users who explicitly confirmed that they would not pay to watch in the future. 3). Among the potential video premium users who might consider to pay in the future, there were $75.5 \%$ who expressed they might pay if the content was interesting. Thus, content was the most important factor in attracting this part of users to change to actual premium users."

In addition, among the 1162 respondents, as to the question "Whether you have purchased digital TV pay channels at present?", there were $71.9 \%$ who answered "No", $19.7 \%$ who answered "Yes", and $8.5 \%$ who answered "Have no idea/unwilling to answer". The proportion of $19.7 \%$ in purchasing digital TV pay channels increased, indicating that although network video (IPTV) had impacts and influences upon the traditional TV, the impacts and influences were still limited to free TV. The network video (IPTV) was unable to provide the professionalized and individualized content as in the pay TV. Thus, the network video was unlikely to bring any vigorous impact. From another perspective, it is indicated, if the pay TV expanded its broadcasting channels, 
such as, mobile phone and internet, it would certainly cause impacts on the network video that merely depended on free content at present.

\section{Conclusion and Discussion}

In order to make the conclusion of the study be more promoted and comparable, here we, first of all, analyze investigation and report on users of network video in the past few years.

Table 9.

\begin{tabular}{|c|c|c|c|}
\hline & $\begin{array}{l}\text { Study Report on } \\
\text { Application of Network } \\
\text { Video by Chinese } \\
\text { Netizens in 2009 (issued } \\
\text { in March, 2010) }\end{array}$ & $\begin{array}{l}\text { Study Report on } \\
\text { Application of Network } \\
\text { Video by Chinese } \\
\text { Netizens in } 2010 \text { (issued } \\
\text { in January, 2011) }\end{array}$ & $\begin{array}{l}\text { Study Report on } \\
\text { Application of Network } \\
\text { Video by Chinese } \\
\text { Netizens in 2011 (issued } \\
\text { in March, 2012) }\end{array}$ \\
\hline Male & $58.10 \%$ & $60.00 \%$ & $57.50 \%$ \\
\hline Female & $14.90 \%$ & $40.00 \%$ & $42.50 \%$ \\
\hline $\begin{array}{l}\text { Below the age } \\
\text { of } 10\end{array}$ & $1.00 \%$ & $30.10 \%$ & $1.60 \%$ \\
\hline 10-19 & $32.90 \%$ & & $27.70 \%$ \\
\hline $20-29$ & $28.60 \%$ & $32.30 \%$ & $31.70 \%$ \\
\hline 30-39 & $21.90 \%$ & $22.50 \%$ & $25.40 \%$ \\
\hline $40-49$ & $10.40 \%$ & $9.30 \%$ & $9.90 \%$ \\
\hline $50-59$ & $3.70 \%$ & $4.40 \%$ & \\
\hline $\begin{array}{l}\text { Above the age } \\
\text { of } 60\end{array}$ & $1.50 \%$ & $1.40 \%$ & $3.60 \%$ \\
\hline $\begin{array}{l}\text { Primary } \\
\text { school and } \\
\text { below }\end{array}$ & $6.30 \%$ & $5.70 \%$ & $7.30 \%$ \\
\hline $\begin{array}{l}\text { Junior middle } \\
\text { school }\end{array}$ & $23.10 \%$ & $21.80 \%$ & $33.70 \%$ \\
\hline $\begin{array}{l}\text { Senior middle } \\
\text { school }\end{array}$ & $40.40 \%$ & $41.50 \%$ & $33.40 \%$ \\
\hline Junior college & $13.90 \%$ & $15.10 \%$ & $11.10 \%$ \\
\hline $\begin{array}{l}\text { Undergraduate } \\
\text { and above }\end{array}$ & $16.30 \%$ & $15.90 \%$ & $14.40 \%$ \\
\hline
\end{tabular}

It was shown by the result that, the audience who watched the network video accounted for approximately $80 \%$ among the age group of 10-39, indicating that mostly young people watched the network video.

In addition, it was shown in "Study Report on Application of Network Video by Chinese Netizens in 2009" promulgated by CNNIC in March 2010, there were $66.8 \%$ of network video users who spent obviously less time to watch TV, compared with their choice in the past, among which $23.7 \%$ of users expressed that they almost did not watch TV for any program of the TV stations. A comparison between watching the network video and watching TV was made to observe their differences in the attitude towards watching a film or a TV play, and it was shown there were $13.1 \%$ network video users who agreed that "they would like more to watch a film or a TV play on the internet". There were more than half of network video users who depended more on internet on TV. $56.7 \%$ of network video users agreed that "I am more dependent on the internet than on the TV" and $26.9 \%$ of respondents strongly agreed with this view. In application of network video, there were $73 \%$ of respondents who agreed that "After acquiring information about a hot broadcast film or TV play, I would immediately surf on the internet to watch the film or TV play." Network video users had a higher degree of acceptance of advertisements and $62.9 \%$ of users expressed that they could accept advertisements in the service of network video. There were $39.9 \%$ of users who expressed that, under the circumstance when the video was not affected (such as, prior to broadcast/ the buffering time during the broadcast, time out, play back end time and any position that would not affect the watch), they could accept the advertisements that appeared during the play of 
the video.

It was shown in "Study Report on Application of Network Video by Chinese Netizens in 2011" (promulgated in January, 2011), the domestic market of paying to watch the network video was in depression. During this survey, there were only $6 \%$ of network video users who had ever paid to watch a video program in the past half year. It was shown by a survey on non-premium users in terms of the intention of pay, $22.4 \%$ of users expressed that they would consider paying if the video program they liked would be paid and $72.9 \%$ of users were accustomed to watching a free video and would not consider paying in the future. It was shown by a survey on the tyles of video programs watched by users who paid, it was high definition film and TV play that were mostly favored by users. 78.8\% of users had ever paid to watch high definition film and TV play in the past half year. And newly-released film was also favored by premium users. $77 \%$ of users had ever paid to watch newly-released film on the internet in the past half year. Other video programs watched by users who paid were successively hot broadcast TV play, sports events collection, entire collection of cartoon, live broadcast of TV program and special subject of entertainment program, etc.

It was shown in "Study Report on Application of Network Video by Chinese Netizens in 2011" (promulgated in March 2010), among the network video users, the proportion of users who watched the video for one day or two every week was the highest, namely, $35.3 \%$, and then was the proportion of users who watched TV each day, namely, $28.5 \%$. Generally speaking, since the video content became increasingly abundant, both long video of film and TV play and short video of original creation by users better satisfied the demand of users and the frequency of network video users in watching the network video was relatively high. However, compared with the frequency in watching the traditional TV, the frequency of watching the network video was still obviously low. Almost $60 \%$ of respondents watched TV each day. By contrast, as for a large number of video network users, they still had not formed a stable habit of watching the network video, and as many as $47.8 \%$ of these network video users were low viscosity users who watched the network video for one day or two every week and even less than one day every week. In 2011, there were only $7.6 \%$ of network video users who had ever paid to watch the network video. And among the users who had ever paid, as many as $73.5 \%$ of users merely paid for once or twice now and then, which indicated that the habit of Chinese netizens in paying to watch the network video at present was still not quite mature. Among a limited number of premium users, the primary reason to compel them to pay to watch the network video was that they were likely to watch better and more resources if they paid, which accounted for a proportion of almost a half (47.9\%). Then, 34.6\% of users had to choose to pay to watch the network video since they indeed were not able to find any free resource, and their behavior was urged. The function of other factors was limited, such as, definition of video and no advertisement, etc. Corresponding with the occasional pay behavior of video premium users, their mode of pay was mainly pay for a single broadcasting on demand and there were $71.9 \%$ of video premium users chose this mode. And the proportion of premium users was only $28.1 \%$ who had a monthly flat rate or annual flat rate. Among the users who had not ever paid to watch the network video, there were approximately three quarters of users who explicitly expressed that they would certainly not pay in the future. The habit of watching the network video free of charge had been around everywhere and fostering of a relevant market would be a long and burdensome process. In addition, there were $25.1 \%$ of users who expressed they might pay to watch the network video, indicating that one quarter of users who had not ever paid did not totally resist the choise of pay and they might pay in the future.

A comparable analysis of finding in this study and finding in the national statistical data reveals that the audiences who use the network video at present have the following common characteristics:

1) The audiences who use the network video are mainly young people at an age of 10 to 39 .

2) Appearance of network video (IPTV) does have influences on the frequency of watching the traditional TV by the audience. From the change of the actual behavior of the watching frequency to perception of influences of the network video (IPTV) on the traditional TV, it can be found that, for the time being, network video (IPTV) is becoming a powerful competitor of the traditional TV which also contains digital pay TV.

3) It is true that more and more audience come into contact with the network video, but the intention of the audience to purchase network video is not strong.

The significance of this study is that, through a survey and analysis, it is found that influences of network video on the traditional TV (including digital pay TV) are that it has appealed young audience to watch, but the 
network video can only attract the audience to watch, and may not attract them to pay to watch. Therefore, the direct influence of network video on pay TV is limited. This is because although the search ability of network video is higher than that of the traditional TV in terms of interactivity, it is difficult for the network video to compete with digital pay TV since its content mainly originates from the free part of the traditional TV. Nonetheless, if the digital pay TV expands its issuance platform to the network, then it will necessarily come into powerful competition with the current free network video and appeal more audience to watch and purchase.

Of course, this study also has the following limitations:

On one hand, this study is limited to questionnaire survey, so whether the effectiveness of such a kind of self-report will be sufficiently enough? Recently, technology in development of measurement of audience has developed an instrument to keep track of the behaviors and habits of network audience. For example, Nielsen Net Rating and com Score have collected the personal data of the audience by means of installing tracking software on the computer of the audience. However, in the process of collecting use of multiple media products by the audience, questionnaire survey is still a rational or most effective instrument.

On the other hand, this study is only limited to make a survey on netizens in Guangzhou by means of QQW. Since QQ is a kind of network instrument, and it is true that a lot of netizens use QQ in China, it does not mean that all netizens use QQ. Therefore, whether the respondents who use QQ can reflect the condition of contact with TV by all netizens in Guangzhou becomes a problem. Besides, even though the respondents who use QQ can represent the condition of contact with TV by netizens in Guangzhou, there is still a gap between their condition and the condition of contact with TV by the common audience in Guangzhou.

Hence, studies within this area should be based on the condition of contact with TV in the case of the common audience in Guangzhou and make a more scientific survey to get more general conclusions.

\section{References}

Deng, Xiaoxuan. (2010). Survey and Analysis of Influencing Factors in Xi'an University Students' Usage of IPTV. Southeast Communication, (4).

Huang, Chuxin. (2008). Change and Reconstruction --- Development Condition and Direction of Chinese IPTV. Beijing: Communication University of China Press.

Huang, Shengmin et al. (2005). New Theory of Operation of Radio and TV Media Industry. Shanghai: Fudan University Press.

Jonathan Taplin. (2005). The IPTV Revolution. The Network Society and the Knowledge Economy: Portugal in the Global Context. A Seminar.

Lv, Liang'an. (2006). Thought on Development of IPTV. Chengdu: Master's Thesis in Sichuan University.

Shi, Changshun. (1999). IPTV and It's Broadcasting Characteristics. Modern Communication.

Shi, Xiaofeng. (2009). Study on Development Condition of Chinese IPTV. Chengdu: Graduate School of Sichuan Academy of Social Sciences.

Wang, Mingxuan. (2009). TV to Die out --- Approaching of Networking and Interactive Video Era. Communication University of China Press.

Zhang, Li. (2010). Communication Effectiveness of Online Video Advertisement and Improvement Stategy: Based on a Survey of College Students' online Video Usage. Advertising Panorama: Theory Version, 5.

\section{Note}

Note 1. Refer to: Agarwal, R. \& Karahanna, E. (2000). Time Flies When You're Having Fun: Cognitive Absorption and Beliefs about Information Technology Usage. Management Information Systems Quarterly. 24 (4), 665-694. Davis, F. (1989). Perceived Usefulness, Perceived Ease of Use, and User Acceptance of Information Technology. Management Information Systems Quarterly. 13 (3), 318-339. Venkatesh, V. (2000). Determinants of Perceived Ease of Use: Integrating Control, Intrinsic Motivation, and Emotion into the Technology Acceptance Model. Information Systems Research. 11 (4), 342-365. 